\title{
Parkinson's Disease with and without REM Sleep Behaviour Disorder: Are There Any Clinical Differences?
}

\author{
Asako Yoritaka $^{\mathrm{a}, \mathrm{b}}$ Hideki Ohizumi $^{\mathrm{a}}$ Shigeki Tanaka $^{\mathrm{a}}$ Nobutaka Hattori $^{\mathrm{b}}$

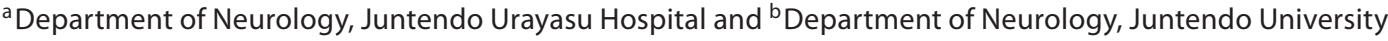 \\ School of Medicine, Tokyo, Japan
}

\section{Key Words}

REM sleep behaviour disorder · Parkinson's disease ·

Autonomic nervous system

\begin{abstract}
Rapid eye movement sleep behaviour disorder (RBD) may serve as a useful indicator to approach Parkinson's disease (PD); however, PD patients do not always exhibit RBD. We wondered whether the presence of RBD would be reflected in the expansion of PD lesions and represent the same PD entity. We examined the clinical differences between PD with and without RBD and studied the frequency of RBD-like symptoms (RBD-s) and clinical differences in 150 PD patients, including 81 patients (54.0\%) who satisfied the International Classification of Sleep Disorders, Revised, minimum clinical criteria for RBD. RBD-s preceding the appearance of parkinsonism were found in $44.4 \%$ of patients. Statistically, the presence of RBD-s was associated with ages above 65 years, male gender, constipation, dopa-induced dyskinesia and 'sleep attack', with odds ratios of 3.709, 2.469, 2.184, 5.046 and 6.562 , respectively. No differences were found between the 2 groups with regard to symptoms at PD onset, disease duration, Hoehn-Yahr stage, hallucination, dementia, wearingoff, orthostatic hypotension, cerebral blood flow and antiparkinsonism drugs. In the early stage, RBD and autonomic system dysfunction are important factors in the progression of PD.

Copyright $\odot 2009$ S. Karger AG, Basel
\end{abstract}

\section{Introduction}

Rapid eye movement (REM) sleep behaviour disorder (RBD) is characterized by a loss of normal skeletal muscle atonia and involves complex motor activity occurring specifically during REM sleep in association with dream mentation. RBD can be idiopathic or can be associated with degenerative neurological disorders, particularly multiple-system atrophy, dementia with Lewy bodies (DLB) and Parkinson's disease (PD) [1]. In previous studies, the histopathology of patients with RBD revealed incidental Lewy body disease [2], while $38 \%$ of RBD patients aged $\geq 50$ years were eventually diagnosed with $P D$ [3]. Since RBD may serve as an early indicator of $\mathrm{PD}$, the detection of this symptom could enable the treatment of $\mathrm{PD}$ with novel drugs to prevent progression to full-blown PD. However, PD patients do not always exhibit RBD; in fact, this symptom is only observed in approximately one third to one half of PD patients $[1,4,5]$. We wondered whether the presence of RBD would be reflected in the pathology of PD and represent the same PD entity. Therefore, we examined the frequency of RBD-like symptoms (RBD-s) in PD patients and investigated the clinical differences between PD with and without RBD-s by clinical interviews.

\section{KARGER}

Fax +4161306 1234 E-Mail karger@karger.ch www.karger.com
(C) 2009 S. Karger AG, Basel

0014-3022/09/0613-0164\$26.00/0

Accessible online at:

www.karger.com/ene
Asako Yoritaka

Department of Neurology, Juntendo University School of Medicine

2-1-1 Hongo, Bunkyo-ku

Tokyo 113-0033 (Japan)

Tel. +81 33813 3111, Fax +81 35800 0547, E-Mail ayori@juntendo.ac.jp 


\section{Methods and Statistical Analysis}

The subjects comprised patients who satisfied Calne's diagnostic criteria for clinically possible or clinically probable PD [6], with Hoehn-Yahr stage I, II, III or IV. PD patients with HoehnYahr stage $V$ were excluded because some patients lived in a nursing home and could not be observed during their nocturnal sleep. Patients with secondary or symptomatic parkinsonism and DLB patients who satisfied the DLB consensus criteria of the Third and Fourth Congress of DLB $[7,8]$ were also excluded. Clinical interviews were answered by the $\mathrm{PD}$ patients and their bed partners or caregivers. We recruited 150 PD patients between June 2006 and May 2007.

The following 3 conditions were investigated: (1) abnormal movements during sleep, assessed by a structured questionnaire to determine the frequency and type of movement (e.g. crying, thrashing the arms and legs about, walking and hitting); (2) a strong urge to move the legs when relaxing and an inability to fall asleep, except during the day (minimal criteria for restless legs syndrome [9]), and (3) 'sleep attack' while engaged in activities such as eating, speaking or driving a car.

The clinical findings were reviewed by board-certified neurologists in our department. The following factors were examined: sex, age, age at onset, initial symptoms, Hoehn-Yahr stage, hallucination, dementia (Mini-Mental Score $<23$ points), wearing-off, dopainduced dyskinesia (DID), orthostatic hypotension (pressor medication), constipation (cathartic medication), restless legs syndrome, order of medications and first medication, anaemia (decreased haemoglobin, $-2 \mathrm{SD})$, the heart-to-mediastinum uptake ratio $(\mathrm{H} / \mathrm{M}$ ratio) of meta-iodobenzylguanidine (MIBG) scintigraphy and cerebral blood flow determined by single-photon-emission computed tomography (SPECT). MIBG scintigraphy using ${ }^{123}$ I-MIBG (111 $\mathrm{MBq}$ ) was used to determine the $\mathrm{H} / \mathrm{M}$ ratio. SPECT with $600 \mathrm{MBq}$ ${ }^{99} \mathrm{mTc}$ (Neurorite) was performed and evaluated by a radiological statistical analysis software (Easy Z-Score Imaging System).

$\mathrm{RBD}$-s were confirmed according to the clinical International Classification of Sleep Disorders, revised (ICSD-R), minimal diagnostic criteria [10]; however, the current criteria require polysomnography. Therefore, the inter-group differences were examined depending on the presence of RBD-s. The differences in clinical demographic characteristics between PD patients with and those without RBD-s (RBD and non-RBD groups, respectively) were compared using an exact test. The inter-group differences with regard to sex, symptoms at onset, hallucination, dementia, constipation, wearing-off, DID, orthostatic hypotension, first medication and anaemia were investigated using Fisher's $\chi^{2}$ test. The levodopa, dopamine agonist, amantadine, selegiline and trihexyphenidyl doses and the Hoehn-Yahr stage were analysed by the Wilcoxon test. Age, age at onset, disease duration and blood flow were analysed by an unpaired t test. A multivariate logistic regression analysis was used to study the individual role of each factor, including age, sex, disease duration and Hoehn-Yahr stage, which exhibited statistically significant differences in the t test and Wilcoxon test. Furthermore, the relationship between the history of RBD and factors such as hallucination, dementia, wearing-off, DID, orthostatic hypotension, constipation, 'sleep attack' and each antiparkinsonism drug was investigated using a logistic model adjusted for age, sex, disease duration and Hoehn-Yahr stage. Values of $\mathrm{p}<0.05$ were regarded as statistically significant. These statistical data were analysed using SPSS version 11 for Windows.

REM Sleep Behaviour Disorder in

Parkinson's Disease

\section{Results}

The mean age of the $150 \mathrm{PD}$ patients (70 men, 80 women) was $68.5 \pm 9.8$ years and that at PD onset was $62.0 \pm$ 10.8 years, with a disease duration of $6.4 \pm 4.6$ years (table 1). The Hoehn-Yahr stage distribution of the patients was as follows: stage I, $\mathrm{n}=3$; II, $\mathrm{n}=26$; III, $\mathrm{n}=96$ and IV, $\mathrm{n}=25$. Of the 150 patients, $13(8.7 \%)$ were not receiving any medication. Levodopa with carbidopa or benserazide was administered as the initial medication to $87(58.0 \%)$ patients and to $123(82.0 \%)$ patients at the time of the interview; the maintenance dose was $330.6 \pm 185.0 \mathrm{mg}$. A dopamine agonist was administered to $19(12.7 \%)$ patients as the initial medication and to $95(63.3 \%)$ patients at the time of the interview. Trihexyphenidyl was administered to $24(16.0 \%)$ patients as the initial medication and to $40(26.7 \%)$ patients at the time of the interview. Amantadine was administered to $9(6.0 \%)$ patients as the initial medication and to $39(26.0 \%)$ patients at the time of the interview. In some cases, these drugs were administered together even at the first medication.

Eighty-one PD patients (54.0\%) met the ICSD-R minimal clinical diagnostic criteria for $\mathrm{RBD}$ (table 1). The duration of RBD-s was $6.8 \pm 10.1$ years. $\mathrm{RBD}$-s preceding the appearance of parkinsonism were reported in $36 \mathrm{pa}-$ tients (44.4\%) in the RBD group. The mean age was higher in the RBD group (70.6 \pm 8.1 years) than in the nonRBD group $(66.0 \pm 11.1$ years; t test, $0.004, \geq 65 / \leq 64$; odds ratio (OR), 3.709; 95\% confidence interval (CI), 1.701-8.087; $\mathrm{p}=0.001)$. The frequency of RBD-s increased with age $(y=-43.09+1.35 x)$. The mean age at the onset of RBD-s was $64.0 \pm 12.2$ years. Men exhibited a higher prevalence of RBD-s; $64.3 \%$ (45 patients) of men and $45.0 \%$ (36 patients) of women had RBD-s (Fisher's exact test, $\mathrm{p}=0.022$; OR, 2.469; 95\% CI, 1.214-5.025; $\mathrm{p}=0.013$ ). The age at $\mathrm{PD}$ onset was $63.5 \pm 9.5$ and $60.2 \pm 12.0$ years in the RBD and non-RBD groups, respectively ( $t$ test, $\mathrm{p}=$ 0.060). The mean duration of parkinsonism was $6.9 \pm$ 4.9 and $5.8 \pm 4.2$ years in the RBD and non-RBD groups, respectively ( $\mathrm{t}$ test, $\mathrm{p}=0.013, \geq 6.0 /<6.0 ; \mathrm{OR}, 1.654 ; 95 \%$ CI, 0.804-3.406; $\mathrm{p}=0.172$ ). The Hoehn-Yahr stage at the examination was $3.0 \pm 0.6$ and $2.8 \pm 0.6$ in the $\mathrm{RBD}$ and non-RBD groups, respectively (Wilcoxon test, $\mathrm{p}=0.050$ ). The duration to progress to the next Hoehn-Yahr stage was $3.4 \pm 2.3$ and $3.3 \pm 2.2$ years in the RBD and non$\mathrm{RBD}$ groups, respectively. In the RBD and non-RBD groups, the symptoms at onset included tremors in 63.0 and $65.2 \%$ of the patients, bradykinesia in 28.4 and $21.7 \%$ of the patients and gait disturbance in 4.9 and $10.1 \%$ of the patients, respectively. Other symptoms included 
Table 1. Patient background and medications according to history and logistic regression of RBD-s

\begin{tabular}{|c|c|c|c|c|c|c|}
\hline \multirow[t]{2}{*}{ Variables } & \multirow{2}{*}{$\begin{array}{l}\text { RBD-s history }(+) \\
(\mathrm{n}=81)\end{array}$} & \multirow{2}{*}{$\begin{array}{l}\text { RBD-s history }(-) \\
(\mathrm{n}=69)\end{array}$} & \multirow{2}{*}{$\begin{array}{l}\text { Comparison } \\
\text { p value }\end{array}$} & \multicolumn{3}{|c|}{ Logistic regression $^{1}$} \\
\hline & & & & $\begin{array}{l}\text { category } \\
\text { point estimate }\end{array}$ & $95 \%$ CI & $\mathrm{p}$ value \\
\hline \multirow{2}{*}{\multicolumn{4}{|c|}{$\begin{array}{l}\text { Background } \\
\text { Age, years }\end{array}$}} & \multirow{2}{*}{\multicolumn{3}{|c|}{$\begin{array}{l}\text { age at interview } \\
\geq 65 / \leq 64\end{array}$}} \\
\hline & & & & & & \\
\hline Interview & $70.6 \pm 8.1$ & $66.0 \pm 11.1$ & $0.004^{2}$ & 3.709 & $1.701-8.087$ & 0.001 \\
\hline PD onset & $63.5 \pm 9.5$ & $60.2 \pm 12.0$ & $0.060^{2}$ & & & \\
\hline RBD onset & $64.0 \pm 12.2$ & - & - & & & \\
\hline \multicolumn{4}{|l|}{ Sex } & \multicolumn{3}{|l|}{ male/female } \\
\hline Male & $45(55.5)$ & $25(36.2)$ & $0022^{3}$ & 2.469 & & \\
\hline Female & $36(44.5)$ & $44(63.8)$ & $0.022^{\circ}$ & & $1.214-5.025$ & 0.013 \\
\hline \multicolumn{4}{|c|}{ Duration of PD at interview, years } & \multicolumn{3}{|l|}{$\geq 6.0 /<6.0$} \\
\hline Mean $\pm S D$ & $6.9 \pm 4.9$ & $5.8 \pm 4.2$ & $0.013^{2}$ & 1.654 & $0.804-3.406$ & 0.172 \\
\hline \multicolumn{4}{|l|}{ Hoehn-Yahr stage } & \multicolumn{3}{|l|}{$\geq \mathrm{III} / \leq \mathrm{II}$} \\
\hline I & $1(1.2)$ & $2(2.9)$ & & 1.083 & & \\
\hline II & $11(13.6)$ & $15(21.7)$ & & & & \\
\hline III & $52(64.2)$ & $44(63.8)$ & $0.050^{4}$ & & $0.435-2.692$ & 0.864 \\
\hline IV & $17(21.0)$ & $8(11.6)$ & & & & \\
\hline Mean $\pm \mathrm{SD}$ & $3.0 \pm 0.6$ & $2.8 \pm 0.6$ & & & & \\
\hline \multicolumn{7}{|c|}{ Medication at interview } \\
\hline \multicolumn{7}{|c|}{ Levodopa, mg/day } \\
\hline No use & $13(18.0)$ & $14(20.3)$ & \multirow{3}{*}{$0.212^{4}$} & & & \\
\hline$<300$ & $34(42.0)$ & $33(47.8)$ & & & & \\
\hline$\geq 300$ & $34(42.0)$ & $22(31.9)$ & & & & \\
\hline \multicolumn{7}{|l|}{ Pergolide, $\mu \mathrm{g} /$ day } \\
\hline No use & $65(80.2)$ & $60(87.0)$ & \multirow{3}{*}{$0.265^{4}$} & & & \\
\hline$<1,000$ & $8(9.9)$ & $5(7.2)$ & & & & \\
\hline$\geq 1,000$ & $8(9.9)$ & $4(5.8)$ & & & & \\
\hline \multicolumn{7}{|c|}{ Cabergoline, mg/day } \\
\hline No use & $60(74.1)$ & $52(75.4)$ & \multirow{3}{*}{$0.712^{4}$} & & & \\
\hline$<3.0$ & $11(13.6)$ & $7(10.1)$ & & & & \\
\hline$\geq 3.0$ & $10(12.3)$ & $12(17.4)$ & & & & \\
\hline \multicolumn{7}{|c|}{ Pramipexole, mg/day } \\
\hline No use & $56(69.1)$ & $50(72.5)$ & \multirow{3}{*}{$0.722^{4}$} & & & \\
\hline$<2.0$ & $15(18.5)$ & $10(14.5)$ & & & & \\
\hline$\geq 2.0$ & $10(12.3)$ & $9(13.0)$ & & & & \\
\hline Selegiline, mg/day & & & & & & \\
\hline No use & $59(72.8)$ & $52(75.4)$ & & & & \\
\hline$<5.0$ & $7(8.6)$ & $5(7.2)$ & $0.746^{4}$ & & & \\
\hline$\geq 5.0$ & $15(18.5)$ & $12(17.4)$ & & & & \\
\hline Amantagine, mg/c & & & & & & \\
\hline No use & $55(67.9)$ & $56(81.2)$ & & & & \\
\hline$<150$ & $6(7.4)$ & $2(2.9)$ & $0.078^{4}$ & & & \\
\hline$\geq 150$ & $20(24.7)$ & $11(15.9)$ & & & & \\
\hline Trihexyphenidyl, & & & & & & \\
\hline No use & $58(71.6)$ & $52(75.4)$ & & & & \\
\hline$<4.0$ & $7(8.6)$ & $5(7.2)$ & $0.616^{4}$ & & & \\
\hline$\geq 4.0$ & $16(19.8)$ & $12(17.4)$ & & & & \\
\hline
\end{tabular}

Figures in parentheses are percentages.

${ }^{1}$ Logistic model adjusted for age, sex, disease duration and Hoehn-Yahr stage. ${ }^{2}$ t test. ${ }^{3}$ Fisher's exact test. ${ }^{4}$ Wilcoxon test. 
Table 2. Symptoms and RBD history

\begin{tabular}{|c|c|c|c|c|c|c|}
\hline \multirow{2}{*}{$\begin{array}{l}\text { Symptom history } \\
\text { after PD onset }\end{array}$} & \multicolumn{2}{|c|}{ History of RBD } & \multirow{2}{*}{$\begin{array}{l}\text { Comparison } \\
\text { Fisher's exact test }\end{array}$} & \multicolumn{3}{|c|}{ Logistic regression $^{1}$} \\
\hline & yes $(n=81)$ & no $(n=69)$ & & OR & $95 \% \mathrm{CI}$ & $\mathrm{p}$ value \\
\hline Hallucination & $21(25.9)$ & $7(10.1)$ & 0.020 & 2.469 & $0.918-6.644$ & 0.074 \\
\hline Dementia & $22(27.2)$ & $9(13.0)$ & 0.097 & 1.473 & $0.574-3.780$ & 0.421 \\
\hline Wearing-off & $19(23.8)$ & $15(19.2)$ & 0.694 & 1.515 & $0.605-3.798$ & 0.375 \\
\hline Dopa-induced dyskinesia & $12(14.8)$ & $3(4.3)$ & 0.053 & 5.046 & $1.148-22.184$ & 0.032 \\
\hline Orthostatic hypotension & $5(6.2)$ & $1(1.4)$ & 0.218 & 2.024 & $0.210-19.504$ & 0.542 \\
\hline Constipation & $55(67.9)$ & $29(42.0)$ & 0.002 & 2.184 & $1.039-4.591$ & 0.039 \\
\hline Restless legs syndrome & $10(12.3)$ & $4(5.8)$ & 0.260 & 1.903 & $0.528-6.851$ & 0.325 \\
\hline Sleep attack & $23(28.4)$ & $3(4.3)$ & 0.000 & 6.562 & $1.747-24.645$ & 0.005 \\
\hline
\end{tabular}

Figures in parentheses are percentages. ${ }^{1}$ Adjusted variables: age at interview, sex, Hoehn-Yahr stage, disease duration.

small voice in $1.2 \%$ of the patients in the RBD group and depression in $1.4 \%$ of the patients in the non-RBD group. No significant differences were observed between the 2 groups with regard to these symptoms.

Hallucination was present in 25.9 and $10.1 \%$ of the RBD and non-RBD groups, respectively ( $\mathrm{p}>0.05)$ (table 2). Dementia was identified in 27.2 and $13.0 \%$ of the $\mathrm{RBD}$ and non-RBD groups, respectively $(\mathrm{p}>0.05)$. Wearing-off was found in 23.8 and $19.2 \%$ of the RBD and nonRBD groups, respectively ( $p>0.05$ ). DID was identified in 14.8 and $4.3 \%$ of the RBD and non-RBD groups, respectively (OR, 5.046; 95\% CI, 1.148-22.184; $\mathrm{p}=0.032$ ). Orthostatic hypotension was found in 6.2 and $1.4 \%$ of the $\mathrm{RBD}$ and non-RBD groups, respectively ( $\mathrm{p}>0.05)$. Constipation was present in 67.9 and $42.0 \%$ of the RBD and non-RBD groups, respectively (OR, 2.184; 95\% CI, 1.0394.591; $\mathrm{p}=0.039$ ). The restless legs syndrome was identified in 12.3 and $5.8 \%$ of the RBD and non-RBD groups, respectively $(\mathrm{p}>0.05)$. 'Sleep attack' was present in 28.4 and only $4.3 \%$ of the RBD and non-RBD groups, respectively (OR, 6.562; 95\% CI, 1.747-24.645; $\mathrm{p}=0.005$ ). Anaemia was present in 21.5 and $12.3 \%$ of the RBD and nonRBD groups, respectively ( $p>0.05$ ). MIBG scintigraphy revealed decreased uptake or accelerated wash-out in 80 of the 84 examined cases. Four (10.3\%) of the 39 patients in the non-RBD group and none of the 45 patients in the $\mathrm{RBD}$ group exhibited negative results in MIBG scintigraphy ( $p>0.05)$. SPECT revealed no differences in the uptake by the pons, substantia nigra, red nucleus and occipital lobe and in the total cerebral blood flow between the 2 groups (table 3 ).

RBD-s resolved over time in $5 \mathrm{PD}$ patients who did not receive clonazepam. In these patients, $\mathrm{RBD}$-s had been
Table 3. SPECT measurement values and history of RBD

\begin{tabular}{llll}
\hline \multirow{2}{*}{$\begin{array}{l}\text { SPECT } \\
\text { measurements }\end{array}$} & \multicolumn{2}{l}{ History of RBD } & $\begin{array}{l}\text { Comparison } \\
\text { t test, } \mathrm{p}\end{array}$ \\
\cline { 2 - 3 } & yes $(\mathrm{n}=81)$ & $\mathrm{no}(\mathrm{n}=69)$ & \\
\hline Total & 23 & 13 & 0.444 \\
Pons right & $43.3 \pm 5.8$ & $44.9 \pm 7.0$ & \\
& 21 & 13 & 0.580 \\
Pons left & $35.7 \pm 14.0$ & $38.6 \pm 16.9$ & \\
& 21 & 13 & 0.572 \\
Nigra right & $35.1 \pm 14.2$ & $38.1 \pm 16.4$ & \\
& 16 & 9 & 0.644 \\
Nigra left & $34.7 \pm 11.2$ & $32.7 \pm 7.4$ & \\
& 16 & 9 & 0.688 \\
Ruber right & $30.4 \pm 14.6$ & $28.3 \pm 8.5$ & \\
& 15 & 10 & 0.183 \\
Ruber left & $33.5 \pm 9.6$ & $39.7 \pm 13.1$ & \\
& 15 & 10 & 0.485 \\
Occipital right & $33.7 \pm 10.9$ & $37.3 \pm 15.1$ & \\
& 21 & 11 & 0.149 \\
Occipital left & $38.3 \pm 11.1$ & $44.7 \pm 12.2$ & \\
& 21 & 11 & 0.671 \\
& $42.0 \pm 10.4$ & $43.1 \pm 11.5$ & \\
\hline
\end{tabular}

present for more than 5 years, and they disappeared after the onset of PD. The cause of this resolution of RBD-s was unclear in 2 cases. Antiparkinsonism drugs alleviated RBD-s in 2 cases and RBD-s disappeared in 1 case after the dose of cabergoline was decreased.

In PD patients, the effect of antiparkinsonism treatment was examined in the following subgroups: patients without RBD-s and patients with RBD-s after the onset of parkinsonism (table 4). Doses of levodopa, pergolide, 
Table 4. Antiparkinsonism drugs and RBD

\begin{tabular}{|c|c|c|c|c|}
\hline \multirow[t]{2}{*}{ Variables } & \multirow[t]{2}{*}{ Category } & \multicolumn{3}{|c|}{ OR of positive history of RBD } \\
\hline & & point estimate & $95 \% \mathrm{CI}$ & $\mathrm{p}$ value \\
\hline \multicolumn{5}{|l|}{ Background } \\
\hline Age, years, at interview & $\geq 65 / \leq 64$ & 3.640 & $1.404-9.438$ & 0.008 \\
\hline Sex & male/female & 2.882 & $1.209-6.868$ & 0.017 \\
\hline Duration of $\mathrm{PD}$, years & $\geq 6.0 /<6.0$ & 3.229 & $1.343-7.762$ & 0.009 \\
\hline Hoehn-Yahr stage & $\geq \mathrm{III} / \leq \mathrm{II}$ & 1.071 & $0.338-3.397$ & 0.907 \\
\hline \multicolumn{5}{|l|}{ Medication at interview } \\
\hline \multirow[t]{2}{*}{ Levodopa, mg/day } & $<300 /$ no use & 1.741 & $0.348-8.702$ & 0.500 \\
\hline & $\geq 300 /$ no use & 1.677 & $0.261-10.788$ & 0.586 \\
\hline \multirow[t]{2}{*}{ Pergolide, $\mu \mathrm{g} /$ day } & $<1,000 /$ no use & 1.320 & $0.341-5.116$ & 0.688 \\
\hline & $\geq 1,000 /$ no use & 1.192 & $0.278-5.106$ & 0.813 \\
\hline \multirow[t]{2}{*}{ Cabergoline, mg/day } & $<3.0 /$ no use & 0.828 & $0.222-3.094$ & 0.779 \\
\hline & $\geq 3.0 /$ no use & 0.616 & $0.191-1.983$ & 0.416 \\
\hline \multirow[t]{2}{*}{ Pramipexole, mg/day } & $<2.0 /$ no use & 1.698 & $0.508-5.678$ & 0.398 \\
\hline & $\geq 2.0 /$ no use & 1.849 & $0.487-7.017$ & 0.366 \\
\hline \multirow[t]{2}{*}{ Selegiline, mg/day } & $<5.0 /$ no use & 1.360 & $0.271-6.828$ & 0.709 \\
\hline & $\geq 5.0 /$ no use & 0.885 & $0.301-2.598$ & 0.824 \\
\hline \multirow[t]{2}{*}{ Amantagine, mg/day } & $<150 /$ no use & 6.360 & $0.965-41.894$ & 0.054 \\
\hline & $\geq 150 /$ no use & 1.328 & $0.473-3.729$ & 0.590 \\
\hline \multirow{2}{*}{ Trihexyphenidyl, mg/day } & $<4.0 /$ no use & 0.762 & $0.171-3.393$ & 0.721 \\
\hline & $\geq 4.0 /$ no use & 1.582 & $0.522-4.793$ & 0.417 \\
\hline
\end{tabular}

Risk for RBD in PD without RBD and with RBD after parkinsonism. Data for drugs were adjusted by variables of age, sex, duration of $\mathrm{PD}$, Hoehn-Yahr stage in logistic regression.

cabergoline, pramipexole, amantadine, selegiline and trihexyphenidyl administered in these 2 subgroups were investigated by logistic regression analysis. The dose of levodopa was considerably higher in patients with RBD-s after parkinsonism than in those without. A comparison by logistic regression analysis revealed no differences in the effect of antiparkinsonism drugs between the 2 subgroups. Moreover, the treatments by antiparkinsonism drugs did not differ between the subgroups.

\section{Discussion}

In this study, $54 \%$ of $\mathrm{PD}$ patients had RBD-s, which is slightly higher than reported in previous studies $[1,4,5]$. $\mathrm{RBD}-\mathrm{s}$ were not always the preceding symptoms; RBD-s preceded parkinsonism in only $26.0 \%$ of all PD patients, and they preceded other symptoms in $44.4 \%$ of $\mathrm{PD}$ patients with RBD-s. Many PD patients were aware of the symptoms of RBD-s when parkinsonism appeared. Olson et al. [11] reported that $52 \%$ of $\mathrm{PD}$ patients developed RBD before parkinsonism. Further, in many cases of neurodegenerative diseases, RBD may precede other symptoms of neurodegenerative diseases. In the PD patients in our study, parkinsonism preceded or was noted at almost the same time as RBD-s.

One of the major limitations of this study was the use of the ICSD-R minimal diagnosis criteria to diagnose $\mathrm{RBD}$ because these criteria do not require polysomnography. The sensitivity of specialized interviews for identifying RBD clinically was good (100\%) in non-PD patients; however, it was poor (33\%) in PD patients $[4,12]$. One of the causes for the lower sensitivity in PD patients was the patients' lack of awareness [4]; therefore, we excluded single patients. Although nocturnal sleep behaviour could not be recorded for all patients, we recorded it for 20 subjects (10 patients each from the RBD and nonRBD groups) on HD video (Sony HDR-SR1) to confirm the presence of RBD-s, and these data agreed with those obtained from each questionnaire. Furthermore, in Japan, elderly couples do not always sleep in the same bedroom; therefore, abnormal sleep behaviour not accompanied by loud sounds may not be recognized. Thus, some patients in the non-RBD group may possibly have had 
$\mathrm{RBD}$, thereby representing false negatives and causing underestimation of the frequency of RBD.

We expected an increased prevalence in male and elderly patients since similar findings have been reported in the case of idiopathic RBD [13]. The symptoms at the onset of PD did not differ between the RBD and nonRBD groups. No difference was observed in the frequency of dementia between the RBD and non-RBD groups, and the mean age was greater in the RBD group (70.6 years) than in the non-RBD group (66.0 years). In the general Japanese population, the frequency of dementia is reported to be $1.9 \%$ in 65 - to 69 -year-old individuals and $4.5 \%$ in 70 - to 74 -year-old individuals [14]; therefore, no differences were indicated.

Pacchetti et al. [15] reported that the presence of RBD in $\mathrm{PD}$ patients was associated with an approximately 3fold increased risk of psychotic disorders. Arnulf et al. [16] suggested that hallucinations and delusions in nondemented PD patients can result from abnormal REM sleep. A dysfunction in the control system of REM sleep exists in hallucinators, and hallucinations represent illusions of dream imagery during waking hours [15-17]. Brain stem lesions were indicated to occur in hallucination [18]; however, in the present study, we did not find a relationship between RBD-s and hallucination or between hallucination and responsible lesions.

DID was a dominant symptom of the RBD group, and the cause of the risk of DID was unknown. Although only a few patients with RBD-s had DID, prevention of the induction of DID in patients with RBD-s should be considered during the treatment of parkinsonism. 'Sleep attack' was a dominant symptom in the RBD group; it might be caused by sleep shortage associated with RBD-s or by the differences in levodopa doses or age. In our study, older patients (OR, 1.143; 95\% CI, 1.034-1.265) with RBD-s with PD (OR, 8.532; 95\% CI, 1.674-43.488) exhibited a relative risk for sleep attacks. If PD patients exhibited 'sleep attacks', we would consider the possibility of RBD$s$ and initiate clonazepam treatment.

We investigated the relationship between RBD-s and drugs in patients with and without RBD-s after parkinsonism. In other words, we examined the possibility that RBD-s were caused by pharmacotherapy after the onset of PD. Levodopa, dopamine agonists (pergolide, cabergoline and pramipexole), amantadine, selegiline and trihexyphenidyl exhibited no significant differences between the 2 groups. This showed that the antiparkinsonism drugs did not cause RBD-s in PD patients after the onset of parkinsonism. However, differences in age and sex were observed between PD patients with and without RBD-s after parkinsonism.

The theory of Braak et al. [19] on the pathological processes of PD has received considerable attention. This theory states that pathological lesions begin in the medulla and eventually ascend to more rostral structures. The pathophysiology of RBD is believed to involve the nucleus reticularis magnocellularis and peri-locus coeruleus in the pons $[12,20]$. These regions correspond to the second-stage lesions of Braak et al., which are presymptomatic for $\mathrm{PD}$, and many reports have described sleep symptoms appearing before parkinsonism $[2,11]$. Moreover, Braak et al. reported the involvement of parasympathetic preganglionic projection neurons of the vagal nerve in sympathetic preganglionic neurons of the spinal cord, and in postganglionic neurons of the coeliac ganglion [21]. In our study, constipation was more frequent in the RBD group than in the non-RBD group. Early clinical signs of RBD and constipation were important factors in the report by Braak et al. in that unmyelinated parasympathetic and sympathetic nerves might be vulnerable regions in the pathogenesis of PD. In this theory, lesions pathologically progress upwards; however, this pathological progression is not always clinically confirmed in all PD patients.

\section{References}

1 Boeve BF, Silber MH, Ferman TJ, Lucas JA, Parisi JE: Association of REM sleep behavior disorder and neurodegenerative disease may reflect an underlying synucleinopathy. Mov Disord 2001; 16:622-630.

-2 Uchiyama M, Isse K, Tanaka K, Yokota N, Hamamoto M, Aida S, Ito Y, Yoshimura M, Okawa M: Incidental Lewy body disease in a patient with REM sleep behavior disorder. Neurology 1995;45:709-712.

\footnotetext{
-3 Schenck CH, Bundlie SR, Mahowald MW: Delayed emergence of a parkinsonian disorder in $38 \%$ of 29 older men initially diagnosed with idiopathic rapid eye movement sleep behaviour disorder. Neurology 1996; 46:388-393.

-4 Eisensehr I, Lindeiner H, Jager M, Noachtar S: REM sleep behavior disorder in sleep-disordered patients with versus without Parkinson's disease: is there a need for polysomnography? J Neurol Sci 2001;186:7-11.
}

\footnotetext{
5 Gagnon JF, Bédard MA, Fantini ML, Petit D, Panisset M, Rompre S, Carrier J, Montplaisir J: REM sleep behavior disorder and REM sleep without atonia in Parkinson's disease. Neurology 2002;59:585-589.

6 Calne DB, Snow BJ, Lee C: Criteria for diagnosing Parkinson's disease. Ann Neurol 1992;32:S125-S127.
} 
7 McKeith IG, Dickson DW, Lowe J, Emre M, O'Brien JT, Feldman H, Cummings J, Duda JE, Lippa C, Perry EK, Aarsland D, Arai H, Ballard CG, Boeve B, Burn DJ, Costa D, Del Ser T, Dubois B, Galasko D, Gauthier S, Goetz CG, Gomez-Tortosa E, Halliday G, Hansen LA, Hardy J, Iwatsubo T, Kalaria RN, Kaufer D, Kenny RA, Korczyn A, Kosaka K, Lee VM, Lees A, Litvan I, Londos E, Lopez OL, Minoshima S, Mizuno Y, Molina JA, Mukaetova-Ladinska EB, Pasquier F, Perry RH, Schulz JB, Trojanowski JQ, Yamada M: Consortium on DLB. Diagnosis and management of dementia with Lewy bodies: third report of the DLB consortium. Neurology 2005;65:1863-1872.

8 Lippa CF, Duda JE, Grossman M, Hurtig HI, Aarsland D, Boeve BF, Brooks DJ, Dickson DW, Dubois B, Emre M, Fahn S, Farmer JM, Galasko D, Galvin JE, Goetz CG, Growdon JH, Gwinn-Hardy KA, Hardy J, Heutink P, Iwatsubo T, Kosaka K, Lee VM, Leverenz JB, Masliah E, McKeith IG, Nussbaum RL, Olanow CW, Ravina BM, Singleton AB, Tanner CM, Trojanowski JQ, Wszolek ZK; DLB/ PDD Working Group: DLB and PDD boundary issues: diagnosis, treatment, molecular pathology, and biomarkers. Neurology 2007; 68:812-819.

-9 Walters AS: Toward a better definition of the restless legs syndrome: the International Restless Legs Syndrome Study Group. Mov Disord 1995;10:634-642.
10 American Sleep Disorders Association: International Classification of Sleep Disorders, Revised: Diagnostic and Coding Manual. Rochester, American Sleep Disorders Association, 1997.

11 Olson EJ, Boeve BF, Silber MH: Rapid eye movement sleep behaviour disorder: demographic, clinical and laboratory findings in 93 cases. Brain 2000;123:331-339.

12 Scaglione C, Vignatelli L, Plazzi G, Marchese R, Negrotti A, Rizzo G, Lopane G, Bassein L, Maestri M, Bernardini S, Martinelli P, Abbruzzese G, Calzetti S, Bonuccelli U, Provini F, Coccagna G; Bologna, Genova, Parma and Pisa Universities group for the study of REM Sleep Behavior Disorder in Parkinson's Disease. REM sleep behaviour disorder in Parkinson's disease: a questionnaire-based study. Neurol Sci. 2005;25:316-321.

13 Boeve BF, Silber MH, Ferman TJ: REM sleep behavior disorder in Parkinson's disease and dementia with Lewy bodies. J Geriatr Psychiatry Neurol 2004;17:146-157.

14 Ohtsuka T: Epidemiology of elderly dementia disease. Seishinigakukenkyujyo gyousekisyu 2005;41:16-19.

15 Pacchetti C, Manni R, Zangaglia R, Mancini F, Marchioni E, Tassorelli C, Terzaghi M, Ossola M, Martignoni E, Moglia A, Nappi G: Relationship between hallucinations, delusions, and rapid eye movement sleep behavior disorder in Parkinson's disease. Mov Disord 2005;20:1439-1448.
16 Arnulf I, Bonnet AM, Damier P, Bejjani BP, Seilhean D, Derenne JP, Agid Y: Hallucinations, REM sleep, and Parkinson's disease: a medical hypothesis. Neurology 2000;55: 281-288.

17 Nomura T, Inoue Y, Mitani H, Kawahara R, Miyake M, Nakajima K: Visual hallucinations as REM sleep behavior disorders in patients with Parkinson's disease. Mov Disord 2003;18:812-817.

18 Brown JW: Hallucinations; in Vinken PJ, Bruyn GW, Klawans HL (eds): Handbook of Clinical Neurology Revised (1). Amsterdam, Elsevier, 1985, pp 351-372.

19 Braak H, Tredici KD, Rub U, de Vos RA, Jansen Steur EN, Braak E: Staging of brain pathology related to sporadic Parkinson's disease. Neurobiol Aging 2003;24:197-211.

-20 Boeve BF, Silber MH, Parisi JE, Dickson DW, Ferman TJ, Benarroch EE, Schmeichel AM, Smith GE, Petersen RC, Ahlskog JE, Matsumoto JY, Knopman DS, Schenck CH, Mahowald MW: Synucleinopathy pathology and REM sleep behavior disorder plus dementia or parkinsonism. Neurology 2003;61: 40-45.

21 Braak H, Sastre M, Bohl JR, de Vos RA, Del Tredici K: Parkinson's disease: lesions in dorsal horn layer I, involvement of parasympathetic and sympathetic pre- and postganglionic neurons. Acta Neuropathol 2007;113: 421-429. 